\title{
PEMANFAATAN AIR BUANGAN AIR CONDITIONER (AC) SEBAGAI AIR BERSIH DI KAMPUS 7 POLTEKKES KEMENKES SEMARANG TAHUN 2017
}

\author{
Tiswan $^{*}$, Djamaluddin Ramlan ${ }^{* *}$ \\ Jurusan Kesehatan Lingkungan, Politeknik Kesehatan Kemenkes Semarang, \\ Jl.Raya Baturaden KM 12 Purwokerto, Indonesia
}

\begin{abstract}
Abstrak
Pemanasan global jmenyebabkan perubahan suhu yang cenderung naik yang diakibatkan oleh emisi $\mathrm{CO}_{2}$.Untuk mengantisipasi pemanasan global dengan pengembangan teknologi, manusia menciptakan alat pendingin ruangan yang disebut Air Conditioner (AC).Tujuan penelitian ini adalah mengetahui jumlah air buangan Air Conditioner (AC) dalam kurun waktu 30 menit dan mengetahui kualitas fisik dan mikrobiologi air buangan Air Conditioner (AC). Metode penelitian yang digunakan adalah penelitian kualitatif bersifat deskriptif dengan pendekatan evaluasi. Beberapa parameter yang diukur antara lain: kualitas fisik dan mikrobiologi air buangan Air Conditioner (AC). Pengumpulan data dengan cara observasi, wawancara, pengumpulan, dan dokumentasi. Data disajikan dalam bentuk tabel, gambar dan lampiran.Hasil replikasi pengukuran debit air buangan Air Conditioner (AC) dari suhu $18^{\circ} \mathrm{C}-26^{\circ} \mathrm{C}$ dengan Air Conditioner (AC) 1 PK=5,42 liter dan 2 PK=18,64 liter.Untuk penampungan air buangan Air Conditioner (AC) 1 PK and 2 PK waktu tampung 24 jam dan 8 jam dapat memenuhi kebutuhan air bersih per orang per hari untuk kebutuhan masyarakat kota sebanyak 150 liter per hari per orang. Pemeriksaan kualitas fisik dan mikrobiologi dari Air Conditioner (AC) 1 PK dan 2 PK sudah memenuhi syarat berdasarkan Permenkes RI No. 32 tahun 2017.Peneliti menyimpulkan dari hasil pemeriksaan kualitas fisik dan mikrobiologi menurut Permenkes RI No.32 tahun 2017 sudah memenuhi syarat. Saran yang dapat diberikan adalah sebaiknya air buangan Air Conditioner (AC) ditampung untuk digunakan sebagai air bersih untuk masyarakat yangbermukim pada daerah yang sulit air.
\end{abstract}

Kata kunci:AC (Air Conditioner); air buangan; PK; kesehatan lingkungan

\begin{abstract}
[THE UTILIZATION OF AIR CONDITIIONER (AC) WASTEWATER AS CLEAN WATER IN CAMPUS $7^{\text {TH }}$ KEMENKES POLTEKKES SEMARANG 2017] AttachmentsGlobal warming effected increasing temperature changes which was caused by $\mathrm{CO}_{2}$ emission. In order to anticipate global warming, with developed technology, human created a room cooler tool called Air Conditioner (AC). The main purpose of this research is to investigate the amount of Air Conditioner (AC) wastewater in 30 minutes, and investigate physical quality and microbiology of Air Conditioner (AC) wastewater. In this research, descriptive qualitative research was used by the researcher with evaluative approach. There were several measured parameters in this research: physical quality and microbiology of Air Conditioner (AC) wastewater. The data collection was done in several techniques that were observation, interview, data collecting, and documentation. The data was described in form of tables, images, and attachments. The replication result of Air Conditioner (AC) wastewater debit measurement with temperature $18^{\circ} \mathrm{C}$ $26^{\circ} \mathrm{C}$ from Air Conditioner (AC) $1 \mathrm{PK}=5,42$ litters and from $2 \mathrm{PK}=18$,64 litters. The storage of Air Conditioner wastewater $1 \mathrm{PK}$ and $2 \mathrm{PK}$ with 8 hour and 24 hours accommodation time can meet the needs of clean water as much as 150 litters for a person per day of a society. For the examination of physical quality and microbiology, Air Conditioner (AC) 1 PK and 2 PK had met the standard requirements based on Permenkes RI No. 32 years 2017. The researcher concluded that from examination result, the physical quality and microbiology depending on Permenkes RI No. 32 years 2017 had alreadymet the standard requirements. The researcher suggests that Air Conditioner (AC) wastewater
\end{abstract}


should be sheltered in order to be used as clean water for the communities that live in areas with a lack of clean water.

Keywords $\quad$ :AC (Air Conditioner); journal; PK;environmenthal health.

\section{Pendahuluan}

Pemanasan global adalah peningkatan gas rumah kaca di atmosfer yang disebabkan oleh kegiatan manusia dan industrilisasi yang meningkatkan efek rumah kaca dan menyebabkan perubahan iklim meliputi kenaikan permukaan laut yang bisa mengancam pulau dan masyarakat-masyarakat pantai, siklus hidrologi yang dapat meningkatkan penyebab banjir dan musim kering.

Pemanasan global juga menyebabkan perubahan suhu yang cenderung naik yang diakibatkan oleh emisi $\mathrm{CO}_{2}$ yang menyebabkan sinar matahari yang tiba ke permukaan bumi tidak menembus kembali ke ruang angkasa karena panas tersebut terperangkap dekat permukaan bumi menghasilkan gejala seperti di rumah kaca, cahaya yang masuk tidak dapat menembus kaca tetapi dipantulkan kembali oleh benda-benda didalam ruangan rumah kaca sebagai gelombang panas, akibatnya suhu didalam ruangan rumah kaca lebih tinggi dari pada suhu di luarnya dan hal tersebut yang dikatakan sebagai efek rumah kaca. Dengan adanya atap kaca ini, pancaran sinar matahari yang masuk berulang kalidipantulkan kembali yang menyebabkan suhu di permukaan bumi naik.

Untuk mengantisipasi hal tersebut dengan pengembangan teknologi pada zaman modern ini manusia menciptakan alat pendingin ruangan yang disebut Air Conditioner (AC).Air Conditioner (AC)merupakan suatu modifikasi pengembangan teknologi mesin pendingin yang dimanfaatkan untuk berbagai tujuan terutama yang bertempat tinggal di wilayah subtropis.Dalam prosesnya, Air Conditioner (AC) menghasilkan air yang merupakan hasil kondensasi atau pengembunan udara dari lingkungan sekitar sehingga air buangan Air Conditioner (AC)mengandung sedikit mineral dan memiliki suhu rendah.

Sumber air yang digunakan manusia untuk memenuhi kebutuhan hidup sehari-hari (seperti memasak, mandi, mencuci baju, mencuci kendaraan, menyiram tanaman) menggunakan air permukaan (sungai, rawa, danau, situ,dan muara), air tanah dan air hujan. Pada zaman sekarang standar hidup masyarakatsudah meningkat dengan pesat dengan adanya produk barang dan peralatan yang dapat memudahkan pekerjaan sehari-hari misalnya mesin cuci, pencuci piring otomatis, alat penyejuk udara (AC), WC bilas otomatis dan lain-lain, maka suplai air bersih,

${ }^{\pi)}$ E-mail: tiswan026@gmail.com

${ }^{* *}$ E-mail: djamaluddiramlan@gmail.com dalam rangka pemenuhan kebutuhan hidup akan air (Ir. Nusa Idaman S 2002 h.14).

Selain sumber air yang disebutkan diatas sumber air bisa diperoleh dari hasil teknologi misalnya dari hasil buangan Air Conditioner (AC) berupa air. Dari hasil penelitian pendahuluan yang dilakukan peneliti diperoleh data pendahuluan penadahan air buangan pada unit Air Conditioner (AC) dengan pendingin 9000Btu/h selama 30 menit $=728 \mathrm{ml}=0,72$ liter, 24 jam $=17,24$ liter ; AC dengan pendingin $18000 \mathrm{Btu} / \mathrm{h}=1.474 \mathrm{ml}=$ 1,47 liter, 24 jam = 35,28 liter yang artinya air buangan Air Conditioner (AC) yang ditampung sekitar 24 jam dapat digunakan untuk memenuhi kebutuhan air bersih 1 orang/hari.

Sedangakan penelitian yang dilakukan oleh Bambang Hari P, dkk di pada tahun 2016 yang mengukur nilai rata-rata TDS, $\mathrm{pH}$, Turbidity untuk kondensat Air Conditioner (AC) secara langsung berturut-turut sebesar 14,3 ppm ; $7 \quad$; 0,77 NTUSementara berdasarkan teori menyatakan bahwa kualitas air buangan AC cenderung dipengaruhi cuaca, analisis parameter mikrobiologi menunjukkan kadar Ecoli yang paling rendah yaitu $<2$ MPN/100 sedangkan Penelitian yang dilakukan oleh Laila Musthiqul F, dkk di Kecamatan Banyumanik, Kabupaten Semarang, Jawa Tengah pada tahun 2009 Sampel air AC dari Pabrik Cocacola di Ungaran ( \pm 50 meter dari jalan raya) nilai konduktivitas 3,1 $\mathrm{SS}$, TDS 1,7 ppm dan $\mathrm{pH}$ 7,09 di Studio foto Walet di Setiabudi $( \pm 15$ meter dari jalan raya) memiliki nilai konduktifitas 4,1 $\mu$ S, TDS 2,3 ppm dan $\mathrm{pH}$ 7,42. Dan air minum isi ulang Fine Jati Raya Banyumanik ( $\pm 8 \mathrm{~km}$ dari jalan raya) konduktifitas 5,87 $\mu \mathrm{S}$, TDS 2,88 ppm dan $\mathrm{pH}$ 7,71.

Atas hasil penelitian pendahuluan peneliti terhadap air buangan Air Conditioner (AC) penulis tertarik untuk mengadakan penelitian di Kampus 7 Poltekkes Kemenkes Semarang sebagai studi pendahuluan. Penulis mengambil judul : "Pemanfaatan Air Buangan Air Conditioner (AC) sebagai air bersih di Kampus 7 Poltekkes Kemenkes Semarang Tahun 2017“. Dengan harapan hasil penelitian dapat menjadi solusi dalam mengurangi pemakaian air bersih.

\section{Bahan dan Metode}

Penelitian ini menggunakan jenis penelitian kualitatif bersifat deskriptif dengan pendekatan evaluasi yang bertujuan untuk mengetahui jumlah air buangan Air Conditioner(AC) dalam kurun waktu 30 menit dan mengetahui kualitas fisik dan mukrobiologi air buanganAir Conditioner(AC) dengan menganalisis 
semua data yang diolah dan dibandingkan dengan Permenkes RI No. 32 tahun 2017 tentang Standar Baku Mutu Kesehatan Air Keperluan Sanitasi, Kolam Renang, Solus Per Aqua dan Pemandian Umum. Pengumpulan data dilakukan dengan cara pengukuran debit air buangan Air Conditioner(AC), observasi, wawancara dan dokumentasi. Instrumentasi yang digunakan berupa gelas ukur, TDS meter, Thermometer, Turbidity meter, timer, botol sampel, Bunsen, alkohol dan es box.

\section{Hasil dan Pembahasan}

Berdasarkan hasil penelitian yang dilakukan pada Air Conditioner (AC) di Kampus 7 Poltekkes Kemenkes Semarang tentang pengukuran debit air buangan Air Conditioner (AC) pada gedung R1, R2, R3, G, E dan B, dapat dilihat pada hasil dan pembahasan sebagai berikut: Hasil pengukuran debit air buangan Air Conditioner (AC) sebagai berikut :

a. Pengukuran Debit Air Buangan Air Conditioner (AC) diRuang Kantor Gedung R1

\begin{tabular}{|c|c|c|c|c|c|c|c|}
\hline \multirow{4}{*}{ No } & \multirow{4}{*}{ Suhu } & \multicolumn{6}{|c|}{ Kantor Jurusan } \\
\hline & & \multirow{2}{*}{\multicolumn{2}{|c|}{$\frac{\text { Kesling }}{2 \mathrm{PK}}$}} & \multirow{2}{*}{\multicolumn{2}{|c|}{$\frac{\text { TRR }}{2 \text { PK }}$}} & \multirow{2}{*}{\multicolumn{2}{|c|}{$\frac{\text { Kebidanan }}{2 \mathrm{PK}}$}} \\
\hline & & & & & & & \\
\hline & & $\mathrm{ml}$ & liter & $\mathrm{ml}$ & liter & $\mathrm{ml}$ & liter \\
\hline 1 & $18^{\circ} \mathrm{C}$ & 2061 & 2,06 & 2093 & 2,09 & 2160 & 21,6 \\
\hline 2 & $19^{\circ} \mathrm{C}$ & 2133 & 2,13 & 2076 & 2,07 & 2087 & 2,08 \\
\hline 3 & $21^{\circ} \mathrm{C}$ & 2146 & 2,14 & 2153 & 2,15 & 2064 & 2,06 \\
\hline 4 & $21^{\circ} \mathrm{C}$ & 2030 & 2,03 & 2120 & 2,12 & 2130 & 2,13 \\
\hline 5 & $22^{\circ} \mathrm{C}$ & 2351 & 2,35 & 2165 & 2,16 & 2043 & 2,04 \\
\hline 6 & $23^{\circ} \mathrm{C}$ & 2069 & 2,06 & 2080 & 2,08 & 1973 & 1,97 \\
\hline 7 & $24^{\circ} \mathrm{C}$ & 2200 & 2,20 & 2120 & 2,12 & 2097 & 2,09 \\
\hline 8 & $25^{\circ} \mathrm{C}$ & 1958 & 1,95 & 1897 & 1,89 & 1875 & 1,87 \\
\hline 9 & $26^{\circ} \mathrm{C}$ & 2162 & 2,16 & 1675 & 1,67 & 2134 & 2,13 \\
\hline
\end{tabular}

Conditioner (AC) yang berada di ruang kantor jurusan kesehatan lingkungan, Tenik Radiodiagnostik dan Radioterapi dan Kebidanan kondisiruangan dalam keadaan kosong tidak ada dosen, karyawan dan mahasiswa yang beraktivitas di dalam ruangan. Suhu luar ruangan $23^{\circ} \mathrm{C}$ dengan kondisi cuaca mendung, suhu yang digunakan $18^{\circ} \mathrm{C}-26^{\circ} \mathrm{C}$ dengan waktu tunggu 10 menit dan waktu tampung 30 menit untuk spesifikasi Air Conditioner (AC) 2 PK karena suhu $27^{\circ} \mathrm{C}-30^{\circ} \mathrm{CAir}$ Conditioner (AC) tidak mengeluarkan air buangan.

b. Pengukuran Debit Air Buangan Air Conditioner (AC) diRuang Kelas Gedung R2 dan R3 Kampus 7 Poltekkes Kemenkes Semarang

\begin{tabular}{lccccccc}
\hline & & \multicolumn{4}{c}{ Kantor Jurusan } \\
\cline { 2 - 7 } No Suhu & Kesling & \multicolumn{2}{c}{ TRR } & \multicolumn{3}{c}{ Kebidanan } \\
\cline { 2 - 7 } & & $1 \mathrm{PK}$ & \multicolumn{1}{c}{$1 \mathrm{PK}$} & \multicolumn{3}{c}{ PK } \\
\cline { 2 - 7 } & $\mathrm{ml}$ & liter & $\mathrm{ml}$ & liter & $\mathrm{ml}$ & liter \\
\hline 1 & $18^{\circ} \mathrm{C}$ & 742 & 0,74 & 700 & 0,7 & 959 & 0,95 \\
\hline 2 & $19^{\circ} \mathrm{C}$ & 738 & 0,73 & 639 & 0,63 & 870 & 0,87 \\
\hline 3 & $21^{\circ} \mathrm{C}$ & 884 & 0,88 & 593 & 0,59 & 746 & 0,74 \\
\hline
\end{tabular}

\begin{tabular}{cccccccc}
\hline 4 & $21^{\circ} \mathrm{C}$ & 830 & 0,83 & 539 & 0,53 & 676 & 0,67 \\
\hline 5 & $22^{\circ} \mathrm{C}$ & 723 & 0,72 & 420 & 0,42 & 668 & 0,66 \\
\hline 6 & $23^{\circ} \mathrm{C}$ & 448 & 0,44 & 376 & 0,37 & 517 & 0,51 \\
\hline 7 & $24^{\circ} \mathrm{C}$ & 917 & 0,91 & 446 & 0,44 & 576 & 0,57 \\
\hline 8 & $25^{\circ} \mathrm{C}$ & 988 & 0,98 & 335 & 0,33 & 450 & 0,45 \\
\hline 9 & $26^{\circ} \mathrm{C}$ & 488 & 0,48 & 311 & 0,31 & 423 & 0,42 \\
\hline
\end{tabular}

Pada saat pengukuran debit air buangan Air Conditioner (AC) yang berada di ruang kelas jurusan kesehatan lingkungan kondisiruangan dalam keadaan kosong tidak ada dosen, karyawan dan mahasiswa yang beraktivitas belajar mengajar di dalam ruang kelas. Suhu luarruangan $20^{\circ} \mathrm{C}$ dengan kondisi cuaca cerah, suhu yang digunakan $18^{\circ} \mathrm{C}-26^{\circ} \mathrm{C}$ dengan waktu tunggu 10menit dan waktu tampung 30 menit untuk spesifikasi Air Conditioner (AC) $1 \mathrm{PK}$ karena suhu $27^{\circ} \mathrm{C}-30^{\circ} \mathrm{C}$ Air Conditioner (AC) tidak mengeluarkan air buangan.

c. Pengukuran Debit Air Buangan Air Conditioner (AC) diGedung B laboratorium Bahasa

\begin{tabular}{|c|c|c|c|}
\hline \multirow[t]{2}{*}{ No } & \multirow[t]{2}{*}{ Suhu } & \multicolumn{2}{|c|}{$\begin{array}{c}\begin{array}{c}\text { Gedung B } \\
\text { Laboratorium } \\
\text { bahasa }\end{array} \\
1 \mathrm{PK}\end{array}$} \\
\hline & & $\mathrm{ml}$ & liter \\
\hline 1 & $18^{\circ} \mathrm{C}$ & 974 & 0,97 \\
\hline 2 & $19^{\circ} \mathrm{C}$ & 938 & 0,93 \\
\hline 3 & $21^{\circ} \mathrm{C}$ & 884 & 0,88 \\
\hline 4 & $21^{\circ} \mathrm{C}$ & 830 & 0,83 \\
\hline 5 & $22^{\circ} \mathrm{C}$ & 723 & 0,72 \\
\hline 6 & $23^{\circ} \mathrm{C}$ & 648 & 0,64 \\
\hline 7 & $24^{\circ} \mathrm{C}$ & 779 & 0,77 \\
\hline 8 & $25^{\circ} \mathrm{C}$ & 478 & 0,47 \\
\hline 9 & $26^{\circ} \mathrm{C}$ & 459 & 0,45 \\
\hline
\end{tabular}

Pengukuran debit air buangan Air Conditioner (AC) yang berada di laboratorium bahasa gedung B kondisiruangan dalam keadaan kosong tidak ada yang beraktivitas di dalam ruangan. Suhu luar ruangan $23^{\circ} \mathrm{C}$ dengan kondisi cuaca cerah, suhu yang digunakan $18^{\circ} \mathrm{C}$ $26^{\circ} \mathrm{C}$ dengan waktu tunggu 10 menit dan waktu tampung 30 menit untuk spesifikasi Air Conditioner (AC) 1 PK karena suhu $27^{\circ} \mathrm{C}-30^{\circ} \mathrm{C}$ Air Conditioner (AC) tidak mengeluarkan air buangan.

d. Pengukuran Debit Air Buangan Air Conditioner (AC) diRuang Kelas Gedung G dan E Kampus 7 Poltekkes Kemenkes Semarang

\begin{tabular}{cccccc}
\hline & & \multicolumn{4}{c}{ Ruang Kelas } \\
\cline { 3 - 6 } No & Suhu & \multicolumn{2}{c}{ Ruang G } & \multicolumn{2}{c}{ Ruang E } \\
\cline { 3 - 6 } & & \multicolumn{1}{c}{$1 \mathrm{PK}$} & \multicolumn{3}{c}{$1 \mathrm{PK}$} \\
\cline { 3 - 5 } & $\mathrm{ml}$ & liter & $\mathrm{ml}$ & liter \\
\hline 1 & $18^{\circ} \mathrm{C}$ & 692 & 0,69 & 673 & 0,67 \\
\hline 2 & $19^{\circ} \mathrm{C}$ & 638 & 0,63 & 668 & 0,66 \\
\hline 3 & $21^{\circ} \mathrm{C}$ & 584 & 0,58 & 576 & 0,57 \\
\hline 4 & $21^{\circ} \mathrm{C}$ & 530 & 0,53 & 500 & 0,5 \\
\hline 5 & $22^{\circ} \mathrm{C}$ & 498 & 0,49 & 459 & 0,45 \\
\hline
\end{tabular}




\begin{tabular}{rrrrrc}
\hline 6 & $23^{\circ} \mathrm{C}$ & 448 & 0,44 & 478 & 0,47 \\
\hline 7 & $24^{\circ} \mathrm{C}$ & 435 & 0,43 & 444 & 0,44 \\
\hline 8 & $25^{\circ} \mathrm{C}$ & 492 & 0,49 & 427 & 0,42 \\
\hline 9 & $26^{\circ} \mathrm{C}$ & 378 & 0,37 & 319 & 0,31 \\
\hline \multicolumn{7}{c}{ saat pengukuran } & debit & air buangan Air
\end{tabular}

Conditioner (AC) yang berada di ruang kelas gedungE dan $G$ jurusan kesehatan lingkungan kondisiruangan dalam keadaan kosong tidak ada dosen, karyawan dan mahasiswa yang beraktivitas belajar mengajar di dalam ruang kelas. Suhu luar ruangan $17^{\circ} \mathrm{C}$ dengan kondisi cuaca cerah, suhu yang digunakan $18^{\circ} \mathrm{C}-26^{\circ} \mathrm{C}$ dengan waktu tunggu 10 menit dan waktu tampung 30 menit untuk spesifikasi Air Conditioner (AC) 1 PK untuk suhu $27^{\circ} \mathrm{C}-30^{\circ} \mathrm{C}$ Air Conditioner (AC) tidak mengeluarkan air buangan.

e. Penghitungan Jumlah dan Replikasi Air Buangan Air Conditioner (AC) diKampus 7 Poltekkes Kemenkes Semarang

\begin{tabular}{cccccc}
\hline & & \multicolumn{4}{c}{ Spesifikasi AC } \\
\cline { 3 - 6 } No Suhu & \multicolumn{2}{c}{1 PK } & \multicolumn{2}{c}{2 PK } \\
\cline { 3 - 6 } & & $\begin{array}{l}\text { Jumlah } \\
\text { debit } \\
\text { (liter) }\end{array}$ & $\begin{array}{l}\text { Repli- } \\
\text { kasi } \\
\text { (liter) }\end{array}$ & $\begin{array}{l}\text { Jumlah } \\
\text { debit } \\
\text { (liter) }\end{array}$ & $\begin{array}{l}\text { Repli- } \\
\text { kasi } \\
\text { (liter) }\end{array}$ \\
\hline 1 & $18^{\circ} \mathrm{C}$ & 4,72 & 0,80 & 6,31 & 2,10 \\
\hline 2 & $19^{\circ} \mathrm{C}$ & 4,45 & 0,74 & 6,28 & 2,09 \\
\hline 3 & $21^{\circ} \mathrm{C}$ & 4,18 & 0,70 & 6,35 & 2,12 \\
\hline 4 & $21^{\circ} \mathrm{C}$ & 3,89 & 0,64 & 6,28 & 2,09 \\
\hline 5 & $22^{\circ} \mathrm{C}$ & 3,29 & 0,54 & 6,35 & 2,18 \\
\hline 6 & $23^{\circ} \mathrm{C}$ & 2,87 & 0,48 & 6,11 & 2,03 \\
\hline 7 & $24^{\circ} \mathrm{C}$ & 3,56 & 0,60 & 6,41 & 2,14 \\
\hline 8 & $25^{\circ} \mathrm{C}$ & 3,14 & 0,53 & 5,71 & 1,90 \\
\hline 9 & $26^{\circ} \mathrm{C}$ & 2,34 & 0,37 & 5,96 & 1,99 \\
\hline & Jumlah & $\mathbf{3 2 , 4 4}$ & $\mathbf{5 , 4 2}$ & $\mathbf{5 5 , 9 6}$ & $\mathbf{1 8 , 6 4}$ \\
\hline
\end{tabular}

Hasil dari perhitungan jumlah dan replikasi air buangan Air Conditioner (AC) di kampus 7 Poltekkes Kemenkes Semarang pada spesifikasi Air Conditioner (AC) 1 PK menghasilkan jumlah debit air buangan Air Conditioner (AC) sebanyak 32,44 liter/30 menit dan hasil replikasi air buangan Air Conditioner (AC) sebanyak 5,42 liter/30 menit dari 6 gedung yang terdiri dari R2 (ruang kelas kesehatan lingkungan dan ruang kelas Teknik Radiodiagnostik dan Radioterapi), R3 (ruang kelas Kebidanan), G, E dan B (Laboratorium Bahasa). Untuk perhitungan jumlah dan replikasi air buangan Air Conditioner (AC) 2 PK menghasilkan jumlah debit air buangan Air Conditioner (AC) sebanyak 55,96 liter/30 menit dan hasil replikasi sebanyak 18,64 liter/30 menit dari gedung R1 (kantor jurusan kesehatan lingkungan, kantor jurusan Teknik Radiodiagnostik Radioterapi dan Kantor jurusan Kebidanan) dengan pengaturan suhu Air Conditioner (AC) dari $18^{\circ} \mathrm{C}-26^{\circ} \mathrm{C}$. f. Konversi Pengukuran Debit Air Buangan Air Conditioner (AC)diKampus 7 Poltekkes

\begin{tabular}{cccccc}
\hline \multirow{2}{*}{ No } & \multirow{2}{*}{$\begin{array}{l}\text { Waktu } \\
\text { tampung }\end{array}$} & \multicolumn{2}{c}{$\begin{array}{c}\text { Apesifikasi } \\
\text { AC }\end{array}$} & \multicolumn{2}{c}{$\begin{array}{c}\text { Persentase } \\
\text { (\%) }\end{array}$} \\
\cline { 3 - 6 } & $\begin{array}{l}\text { 1 PK } \\
\text { (liter) }\end{array}$ & $\begin{array}{c}\text { 2 PK } \\
\text { (liter) }\end{array}$ & 1 PK & 2PK \\
\hline 1 & 30 menit & 5,42 & 18,64 & $3,61 \%$ & $12,42 \%$ \\
\hline 2 & 1 jam & 10,84 & 37,28 & $7,22 \%$ & $24,8 \%$ \\
\hline 3 & 8 jam & 4,45 & 0,74 & $57,8 \%$ & $>100 \%$ \\
\hline 4 & 24 jam & 4,18 & 0,70 & $>100 \%$ & $>100 \%$ \\
\hline \multicolumn{3}{c}{ Hasil konversi debit air buanganAir Conditioner }
\end{tabular}

(AC) di kampus poltekkes kemenkes semarang untuk spesifikasi Air Conditioner (AC) 1 PK untuk waktu tampung 30 menit di dapat hasil sebanyak 5,42 liter $=3,61 \%$, 1 jam sebanyak 10,84 liter $=7,22 \%$, 8 jam sebanyak 57,81 liter dan 24 jam sebanyak 173,44 liter hasil persentase $>100 \%$. Spesifikasi Air Conditioner (AC) 2 PK untuk waktu tampung 30 menit di dapat hasil sebanyak 18,64 liter=12,42\%, 1 jam sebanyak 37,28 liter=24,85\%, 8 jam sebanyak 298,24 liter dan 24 jam sebanyak 298,24 liter dan 894,72 liter hasil persentase > $100 \%$.

g. Pemeriksaan Kualitas Air BuanganAir Conditioner (AC) secara Fisik dan Mikrobiologi

\begin{tabular}{|c|c|c|c|c|c|c|}
\hline \multirow[t]{2}{*}{ No } & \multirow{2}{*}{\multicolumn{2}{|c|}{ parameter }} & \multicolumn{2}{|c|}{$\begin{array}{l}\text { Hasil dan } \\
\text { spesifikasi AC }\end{array}$} & \multirow[t]{2}{*}{ NAB } & \multirow[t]{2}{*}{ Ket } \\
\hline & & & $1 \mathrm{PK}$ & $2 \mathrm{PK}$ & & \\
\hline \multirow[t]{5}{*}{1} & Fisik & Bau & $\begin{array}{l}\text { Tidak } \\
\text { berbau }\end{array}$ & $\begin{array}{l}\text { Tidak } \\
\text { berbau }\end{array}$ & - & MS \\
\hline & & Rasa & $\begin{array}{l}\text { Tidak } \\
\text { berasa }\end{array}$ & $\begin{array}{l}\text { Tidak } \\
\text { berasa }\end{array}$ & - & MS \\
\hline & & $\overline{\text { Warna }}$ & $<0,2$ & $<0,2$ & $\begin{array}{l}50 \\
\text { TCU }\end{array}$ & MS \\
\hline & & $\begin{array}{l}\text { Keke- } \\
\text { ruhan }\end{array}$ & 0,22 & 0,13 & $\begin{array}{l}25 \mathrm{~N} \\
\mathrm{TU}\end{array}$ & MS \\
\hline & & $\overline{T D S}$ & 17 & 10 & $\begin{array}{l}1000 \\
\mathrm{mg} / \mathrm{l}\end{array}$ & MS \\
\hline 2 & $\begin{array}{l}\text { Mikro } \\
\text { biologi }\end{array}$ & $\begin{array}{l}\text { Colifor } \\
m\end{array}$ & 0 & 0 & $\begin{array}{l}50 \mathrm{C} \\
\mathrm{FU} \\
/ 100 \\
\mathrm{ml}\end{array}$ & MS \\
\hline
\end{tabular}

Hasil pemeriksaan kualitas air buangan Air Conditioner dengan spesifikasi Air Conditioner (AC)1 PK dan 2 PK didapatkan hasil pemeriksaan parameter fisik dan mikrobiologi yang memenuhi syarat sesuai dengan Permenkes RI No. 32 tahun 2017 tentang Standar Baku Mutu Kesehatan Air Keperluan Sanitasi, Kolam Renang, Solus Per Aqua dan Pemandian Umum.

\section{Kesimpulan}

Berdasarkan hasil penelitian dan pembahasan dapat diambil simpulan sebagai berikut : 
a. Replikasi air buangan Air Conditioner(AC) 1 PK dari suhu $18^{\circ} \mathrm{C}-26^{\circ} \mathrm{C}$ diperoleh hasil air buangan Air Conditioner (AC) 0,80-0,39 liter/30 menit dan spesifikasi Air Conditioner (AC) 2 PK dari suhu $18^{\circ} \mathrm{C}-26^{\circ} \mathrm{C}$ diperoleh 2,10-1,99 liter/30 menit. Untuk penampungan air buangan Air Conditioner (AC) spesifikasi 1 PK hasil tampung 24 jam dapat memenuhi kebutuhan air bersih per orang per hariuntuk kebutuhan masyarakat perkotaan sebanyak 150 liter per hari per orang dan waktu tampung 8 jam dan 24 jam untuk spesifikasi Air Conditioner (AC) 2 PK.

b. Kualitas air buangan Air Conditioner (AC) berdasarkanPermenkes RI No. 32 tahun 2017 tentang Standar Baku Mutu Kesehatan Air Keperluan Sanitasi, Kolam Renang, Solus Per Aqua dan Pemandian Umum pemeriksaan secara fisik spesifikasi Air Conditioner (AC) 1 PK :

1) Bau air buangan Air Conditioner (AC)memenuhi syarat dengan hasil pemeriksaan secara organoleptik tidak berbau.

2) Rasa air buangan Air Conditioner (AC)memenuhi syarat memenuhi syarat dengan hasil pemeriksaan secara organoleptik tidak berasa.

3) Warna air buangan Air Conditioner (AC)memenuhi syarat dengan hasil pemeriksaan $<0,2$ TCU (Kadar maksimum: 50 TCU).

4) Kekeruhan air buangan Air Conditioner (AC)memenuhi syarat didapat hasil pemeriksaan 0,22 NTU (Kadar maksimum: 25 NTU).

5) Zat padat terlarut (TDS) air buangan Air Conditioner (AC)dengan hasil pemeriksaan $17 \mathrm{mg} / \mathrm{l}$ (Kadar maksimum: $1000 \mathrm{mg} / \mathrm{l})$.

c. Kualitas air buangan Air Conditioner (AC) berdasarkan Permenkes RI No. 32 tahun 2017 tentang Standar Baku Mutu Kesehatan Air Keperluan Sanitasi, Kolam Renang, Solus Per Aqua dan Pemandian Umum pemeriksaan secara fisik spesifikasi Air Conditioner (AC) 2 PK :

1) Bau air buangan Air Conditioner (AC)memenuhi syarat dengan hasil pemeriksaan secara organoleptik tidak berbau.

2) Rasa air buangan Air Conditioner (AC)memenuhi syarat memenuhi syarat dengan hasil pemeriksaan secara organoleptik tidak berasa.

3) Warna air buangan Air Conditioner (AC)memenuhi syarat dengan hasil pemeriksaan $<0,2$ TCU (Kadar maksimum: 50 TCU).

4) Kekeruhan air buangan Air Conditioner (AC)memenuhi syarat didapat hasil pemeriksaan 0,13 NTU (Kadar maksimum: 25 NTU).

5) Zat padat terlarut (TDS) air buangan Air Conditioner (AC)dengan hasil pemeriksaan $10 \mathrm{mg} / \mathrm{l}$ (Kadar maksimum : $1000 \mathrm{mg} / \mathrm{l})$.

d. Kualitas mikrobiologi (Bakteri Coliform) air buangan Air Conditioner (AC)1 PK dan 2 PK memenuhi syarat dengan jumlah MPN Coliform 0 CFU/100 ml (Kadar maksimum: 50 CFU/100 ml).

\section{Ucapan Terima Kasih}

Peneliti mengucapkan banyak terima kasihkepada kepala Jurusan Kesehatan LingkunganPoliteknik Kesehatan Kemenkes Semarang yang telah memberikan ijin penelitian di Kampus 7 Poltekkes Kemenkes Semarang serta semua pihak yang telah membantu terselesaikannya penelitian ini.

\section{Daftar Pustaka}

Bambang Hari P dkk, 2016.Studi Pemanfaatan Air Conditioner (AC) Menjadi Air Layak Minum Tahun 2016, Seminar Nasional Teknik Kimia:Dosen mata kuliah kimia.

Dirjen Pemberantasan Penyakit Menular dan Penyehatan Lingkungan Pemukiman, 1997.

Djasio Sanropiedkk, 1984.Penyediaan Air Bersih, Akademi Pemilik Kesehatan Tenaga Sanitasi Pusdiklat:Depkes R.I

Hefni Effendi, 2003. Telaah Kualitas Air Bagi Pengelolaan Sumber Daya Dan Lingkungan Perairan, Yogyakarta: Kanisius

http://air-conditionerariffandisaputra.blogspot.co.id./ 2002/03/bab-iii-pengetahuan-dasar-ac.html?m=1 tanggal 9-02-2017

Kamus Bahasa Indonesia Edisi kedua, 1991

Laila Mustahiqul Falah dkk, 2009.Pembuatan AquaDM (Aquademineralized)dari Air AC (Air Conditioner) Menggunakan Resin Kation dan Anion Tahun 2009, Jurnal Skipsi Penelitian,

Lembar kerja Praktikum Penyehatan Air dan Pengolahan Limbah Cair-A, 2015.

Lembar kerja Praktikum Mikrobiologi, 2014.

Peraturan Menteri Kesehatan Republik Indonesia Nomor 32 Tahun 2017 tentang Standar Baku Mutu Kesehatan Lingkungan dan Persyaratan Kesehatan Air untuk Keperluan Hygiene Sanitasi, Kolam Renang, Solus Per Aqua, dan Pemandian Umum.

Peraturan Pemerintah Republik Indonesia Nomor 82 Tahun 2001 tentang Pengendalian Kualitas Air dan Pengendalian Kualitas Pencemaran

Peraturan Pemerintah Republik Indonesia Nomor 20 Tahun 1990 tentang Mengelompokan Kualitas Air Menjadi Beberapa Golongan Menurut Peruntukannya.

Sugeng Abdullah dkk, 2010.Bahan Ajar Laboratorium Kesling.

Srikandi Fardiaz, 1992. Polusi Air Dan Udara.Yogyakarta.

Sutrisno Totok dkk, 2006.Teknologi Penyediaan Air Bersih. Jakarta: PT Rineka Cipta.

Tutut Mugi Rahayu, 2014. Kualitas Air Bersih Pada Sumur Gali Di Dusun Japun Desa Kewangunan 
Kecamatan Petanahan Kabupaten Kebumen Tahun 2014, KTI,Purwokerto;Jurusan Kesehatan Lingkungan Purwokerto.

Tri Cahyono, 2014. Pedoman Penulisan Proposal dan Karya Tulis Ilmiah, Purwokerto: JKL Kemenkes Purwokwerto.

Undang-undang Republik Indonesia Nomor 7 Tahun 2001 teantang Sumber Daya Air. 